\title{
The effect of the dam-calf relationship on serostatus to Neospora caninum on 20 Costa Rican dairy farms
}

\author{
J.J. Romero ${ }^{\mathrm{a}, \mathrm{b}, *}$, K. Frankena ${ }^{\mathrm{b}}$ \\ a Programa de Investigación en Medicina Poblacional, Escuela de Medicina Veterinaria, \\ Universidad Nacional, P.O. Box 304-3000 Heredia, Costa Rica \\ ${ }^{\mathrm{b}}$ Quantitative Veterinary Epidemiology Group, Wageningen Institute of Animal Sciences, Wageningen \\ University and Research Centre, P.O. Box 338, 6700 AH Wageningen, The Netherlands
}

Received 15 December 2002; received in revised form 5 March 2003; accepted 31 March 2003

\begin{abstract}
An epidemiological study was conduced on 20 dairy herds previously diagnosed as seropositive for Neospora caninum. The number of females per farm varies from 41 to 296 . All females present on the farms were bled once in the period of July and August 2000. A total of 3002 females were bled. An indirect ELISA was used to determine the serostatus of the animals. The analysis of the data was performed in four steps: (1) descriptive statistics about the serological status and general characteristics of the cattle; (2) calculation of vertical and horizontal transmission; (3) an univariate analysis and, (4) a multivariate logistic regression analysis with herd as random effect. The within-herd seroprevalence varied between $25.0 \%$ (34/136) and 70.5\% (203/288). Seven hundred and forty-seven dam-daughter pairs were available, involving daughters of any age. Daughters in the specific age-class of 2- and 3-years old had a higher seroprevalence $(P<0.01)$ compared with younger and older age-classes. The risk of being seropositive when being born to a mother that tested seropositive (prevalence ratio (PR)) was 2.8 -fold increased which coincides with a 5.3 -fold increased odds. The probability of horizontal infection amounts to 0.22 . The probability of a seropositive offspring due to vertical transmission was 0.64 (attributable fraction among exposed $\left.\left(A F_{\text {exp }}\right)\right)$. The multivariate logistic regression showed a significant 6.0 -fold increased odds for being seropositive when born from a seropositive mother. Also the within-herd seroprevalence level was significantly associated with the serostatus of the daughters. In the specific conditions of the dairy herds involved in this study, the serostatus of the cows should be not used as a predictor of the serostatus of daughters due to the increased probability of horizontal transmission.
\end{abstract}

(C) 2003 Elsevier Science B.V. All rights reserved.

Keywords: Neospora caninum; Vertical and horizontal transmission; Serostatus; Dairy cattle; Epidemiology

\footnotetext{
* Corresponding author. Tel.: +506-237-7833; fax: +506-260-2155.

E-mail address: jromero@ns.medvet.una.ac.cr (J.J. Romero).
} 


\section{Introduction}

Neosporosis is a recently recognised parasitic (protozoan) disease caused by Neospora caninum. This disease affects a wide range of animals and has effects on cattle reproduction. It causes foetal losses by resorption, mummification or abortion between the 4th and the 9 th month of pregnancy (Dubey, 1999). Since the first report of Neospora-associated abortion in cattle (Thilsted and Dubey, 1989), many studies have reported N. caninum as a causative agent of abortion around the world (Anderson et al., 1995; Otter et al., 1995; Boulton et al., 1995; Dubey et al., 1997; Thurmond et al., 1997; Venturini et al., 1999; Wouda et al., 1999a,b; Jenkins et al., 2000). In Costa Rica neosporosis has been diagnosed and associated with bovine abortion since 1996 (Pérez et al., 1998; Romero et al., 2000).

The life cycle of Neospora was elucidated in 1998, when the dog was recognised as the definitive host (McAllister et al., 1998). Therefore, dogs may play an important role in the introduction and maintenance of the infection in herds (Dubey, 1999). Two means of transmission among cattle are assumed: vertical and horizontal. The vertical mode (transplacentally from the mother to her calf) is the most prevalent means of transmission (Paré et al., 1996; Thurmond et al., 1997; Schares et al., 1998; Venturini et al., 1999; Davison et al., 1999a). Horizontal transmission has not been documented until recently. Some authors report findings that suggest that horizontal transmission is possible by means of ingestion of feed or water contaminated with Neospora oocysts (McAllister et al., 1998; De Marez et al., 1999; Wouda et al., 1999b; Dubey, 1999; Anderson et al., 2000; Bergeron et al., 2000). Another suggested means of horizontal transmission in newborn calves is by ingestion of colostrum contaminated with tachyzoites, especially in the first hours of life (Uggla et al., 1998). Ingestion of infected amniotic fluid or infected placenta have been proposed in other studies as potential routes of infection (Ho et al., 1997; Piergili-Fioretti et al., 2000; Bergeron et al., 2001); however, these suggested means of infection in cows remain to be proven, despite evidence for this in dogs (Dijkstra et al., 2001).

It is widely accepted that abortion due to neosporosis is the result of a lethal infection of the foetus following a maternal parasitaemia. However, an intra-uterine infection with $N$. caninum will not always induce foetal loss. Factors such as the timing of the parasitaemia during gestation, the quantity and duration of the parasitaemia, the effectiveness of the maternal immune response and the ability of the foetus to mount an immune response have been recognised as crucial factors that determine the fate of the foetus (Hemphill et al., 2000). The acquisition of infection in the third trimester of gestation allows the foetus to develop a sufficient grade of immunocompetency to limit the parasite multiplication, resulting in a calf that will be born clinically healthy (Williams et al., 2000).

Several studies in which $N$. caninum antibodies were measured before colostrum intake by calves report that between 81 and $95 \%$ of seropositive cows gave birth to seropositive calves (Paré et al., 1996; Wouda et al., 1998; Davison et al., 1999a). On the other hand, in a cross-sectional study there was not a clear relationship between the serologic status of dam and offspring, resulting in proportions of seropositive daughters born from seropositive dams ranging from 0 to $85 \%$ (Bergeron et al., 2000).

Other cross-sectional studies have focused on the proportions of seropositive daughters born to seronegative dams in an effort to document postnatal acquisition of Neospora. Thus, Dyer et al. (2000) using IFAT to detect antibodies for Neospora reported that $77.9 \%$ 
(120/154) of seronegative dams had seronegative daughters, while the rest of seronegative dams (22.1\%) had seropositive daughters. In the same way, Dijkstra et al. (2001), using an ELISA based on a detergent lysate of whole sonicated tachyzoite, reported that $83.5 \%$ (207/248) of seronegative dams had seronegative daughters and $16.5 \%(41 / 248)$ had seropositive daughters.

The objective of our study was to assess the mother-calf relationship with regard to serological reactivity to Neospora in 20 Costa Rican dairy herds. We investigated whether the serological status of the dam, could be used as a predictor for the serological status of the calf. If so, this prediction might be used as potential criterion for selective culling.

\section{Materials and methods}

\subsection{Study population}

In this study, 20 dairy farms previously diagnosed as seropositive to Neospora were used. The farms were located between 1500 and $2200 \mathrm{~m}$ above sea level, the temperature range were between 12.9 and $28{ }^{\circ} \mathrm{C}$ and the relative humidity oscillated between 77 and $93 \%$. There were two clearly defined seasons, which were dry and rainy. The total rain precipitation was approximately $500 \mathrm{~mm}$ in the dry season and $3500 \mathrm{~mm}$ in the rainy season. The farms involved in this study were selected intentionally. Since 1986 they participated in a research project focused on dairy production and herd health, and all of them used VAMPP 5.1 (Veterinary Automated Management and Production control Programme, [Noordhuizen and Buurman, 1984]) as their management information system. The most frequent breeds in these herds were Holstein-Friesian, Jersey and crosses between these. The number of females (cows and calves) per farm varied from 41 to 296.

\subsection{Data collection}

All females present in the selected farms were bled once in the period of July/August 2000. Sera were stored at $-20^{\circ} \mathrm{C}$ until assay. An indirect ELISA (Paré et al., 1995) with 87.8\% sensitivity (CI 95\%: 81.3-94.3) and 96.4\% specificity (CI 95\%: 93.3-99.5) for detection of antibodies against Neospora was used to determine the serologic status of the animals (Romero et al., 2002).

VAMPP 5.1 was used as the source of basic data (animals per farm, identification of the cow, age, breed, date of birth, days of gestation at the moment of sampling and genealogy of the cows). Dam-daughter pairs were extracted from VAMPP and merged with a file containing the ELISA results.

\subsection{Data analysis}

Descriptive statistics about the general characteristics of the cattle, regarding the serological status, especially for the dam-daughter pairs, were performed using STATA ${ }^{\circledR}$ (StataCorp., 1999). 
Table 1

Contingency $(2 \times 2)$ table to explain the way of calculation of vertical and horizontal transmission of the disease as was performed in this study

\begin{tabular}{lll}
\hline Status of daughters & Status of dam & \\
\cline { 2 - 3 } \cline { 2 - 3 } & Seropositive & Seronegative \\
\hline Seropositive & $a$ & $b$ \\
Seronegative & $c$ & $d$ \\
& $a+c$ & $b+d$ \\
\hline
\end{tabular}

\subsubsection{Calculation of vertical and horizontal transmission}

The overall probability of horizontal transmission, calculated as the proportion of seropositive daughters born from seronegative dams with its exact binomial $95 \%$ confidence interval (95\% CI) was assessed using EpiInfo 6.0 (Center for Disease Control and Prevention, USA).

The probability of vertical transmission was calculated in several steps. In order to carry out this calculation we used a contingency $(2 \times 2)$ table in which the seropositivity of the dams was defined as exposure (Table 1). As it is a cross-sectional study, with plausible evidence of horizontal transmission, we assumed that a proportion of seropositive dams $(a+c)$ were horizontally infected after the date the calf was born. Therefore the "crude" frequencies were adjusted in the following way. First, the proportion of daughters that was horizontally infected $(b / b+d)$ was calculated. Next, the frequencies of $a, c$ and $(a+c)$ were reduced according to this proportion while these subtracted numbers were added to $b$, $d$ and $(b+d)$, respectively. For both the crude and adjusted frequencies the probabilities of vertical transmission using the attributable fraction among exposed $\left(\mathrm{AF}_{\mathrm{exp}}\right)$ were calculated. $\mathrm{AF}_{\text {exp }}$ represents the proportion of daughters that were seropositive due to being born from seropositive mothers. Confidence intervals for these proportions were calculated with EpiInfo 6.0 (Center for Disease Control and Prevention, USA).

\subsubsection{Univariate analyses}

Age-specific seroprevalences of daughters and mothers were calculated using age categories of 1 year each, except for calves under 1-year old which were divided in two categories: under 150 days old and between 151 and 365 days old. Cows of more than 7-years old were grouped in the same age-class. Differences between proportions of seropositives by age-class were tested by means of the $\chi^{2}$ statistic using EpiInfo 6.0 (Center for Disease Control and Prevention, USA).

In order to eliminate the effect of possible false positives by maternal antibodies in daughters (Davison et al., 1999b; Tizard, 2000), the age of daughters was categorised in two levels, 150 days or less, and older than 150 days. A new data set keeping pairs with daughters older than 150 days was constructed. Furthermore, to assess the effect of the within-herd seroprevalence on the means of transmission of the disease, herds were divided in three categories. Herds with seroprevalence between 25 and 35\% were classified as 'low', herds with seroprevalence between 35.1 and $45 \%$ were classified as 'medium' and herds with seroprevalence higher than $45.1 \%$ were classified as 'high'. A contingency table for pairs in each subset was constructed to calculate the probability of horizontal transmission. 
The prevalence ratio (PR) as measure of association and the $\mathrm{AF}_{\text {exp }}$ as measure of effect of the exposure to seropositive dams were calculated using the epidemiological software WinEpiscope 2.0 (Thrusfield et al., 2001).

\subsubsection{Multivariate analysis}

Finally, a multivariate logistic regression model with herd as random effect was used to assess the relationship between the serostatus of the daughter and her age, the serostatus of the mother and the within-herd seroprevalence (STATA ${ }^{\circledR}$ release 6.0, StataCorp., 1999). The multivariate analysis can only be carried out on unadjusted frequencies, because we do not know which mothers were horizontally infected after the calf was born.

\section{Results}

\subsection{Seroprevalence}

A total of 3002 females were bled on the 20 farms studied. The overall seroprevalence for Neospora was $39.7 \%$ (1191/3002), whereas the within-herd seroprevalence varied between $25.0 \%(34 / 136)$ and $70.5 \%$ (203/288). Taking the sensitivity and specificity of the test into account, the overall prevalence is $42.8 \%$.

Seven hundred and forty-seven dam-daughter pairs were available for analysis. In the group of daughters, $614(82.2 \%)$ were less than 2 years old, whereas $711(95.2 \%)$ were younger than 3 years old. In the group of dams, $684(91.5 \%)$ were more than 3 years old. Apparent seroprevalences in daughters and dams were $33.3 \%$ (249/747) and 38.2\% (285/747), respectively. For the age categories of dams the seroprevalence varied between 33.8 and $44.3 \%$, with no statistical differences between age categories (Fig. 1). Daughters in

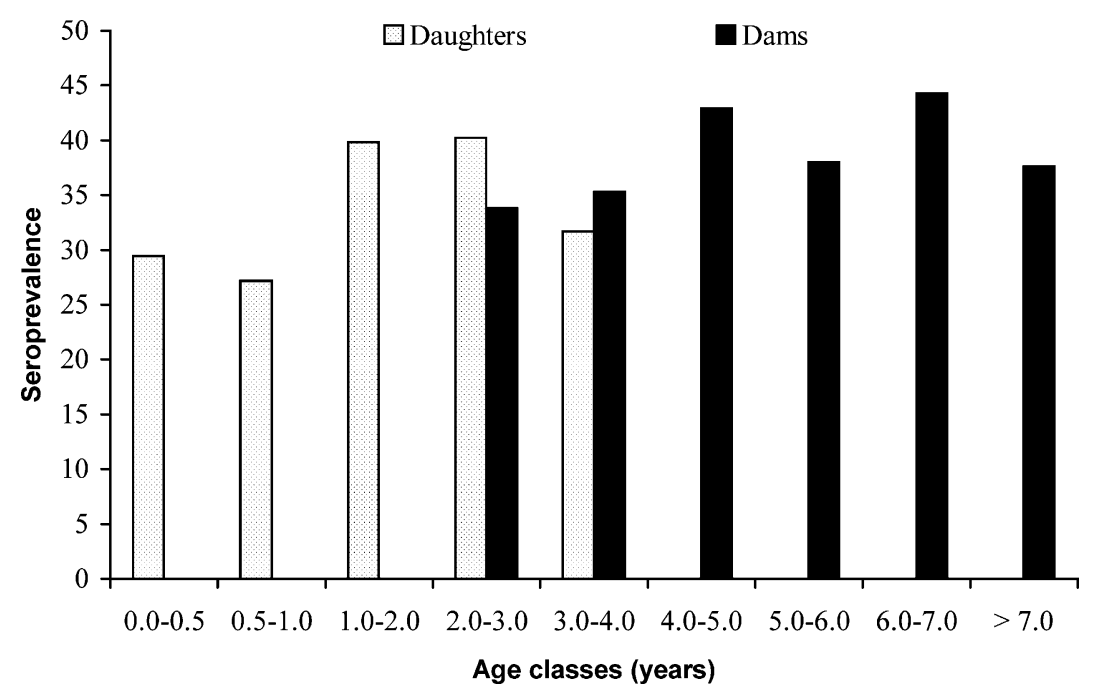

Fig. 1. Seroprevalence in dams and daughters by age groups. 


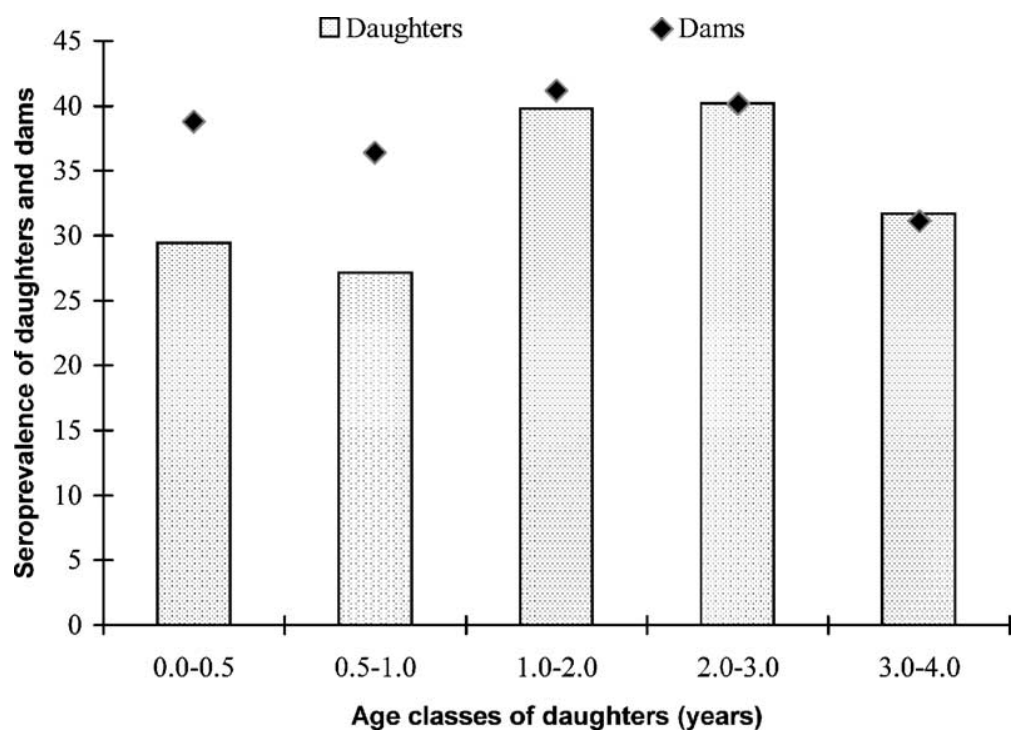

Fig. 2. Seroprevalence for daughters and their dams, by age-groups of daughters, at the date of sampling. Seropositive daughters born from seropositive or negative dams and negative daughters born from seropositive or negative dams were present in each age-group.

the specific age-class of 2 and 3-years old had a higher seroprevalence $(P<0.01)$ compared with the other age-classes, but not among them. Furthermore, there were no differences in seroprevalence between the other age-classes (Fig. 1). In all age-classes of daughters there were seropositive and seronegative daughters that were born from seropositive or seronegative dams. Furthermore, the percentage of seropositive dams (around 38.0\%) within the age categories of daughters was not significantly different $(P>0.5)$ (Fig. 2).

\subsection{Association between serostatus of daughters and dams}

Results of the 747 pairs are shown in Table 2. The risk of being seropositive is 2.8 -fold increased when being born from a mother that is tested seropositive (prevalence ratio) which coincides with a 5.3-fold increased odds, both measures are based on the adjusted numbers.

The probability of horizontal transmission is 0.22 (110/512). Of seropositive daughters born from seropositive mothers, $63.7 \%$ is due to the fact that their mothers were seropositive $\left(\mathrm{AF}_{\mathrm{exp}}\right)$, which is the probability of seropositive offspring due to vertical transmission.

From the general data set containing 747 pairs, a subset with 542 pairs was selected excluding daughters younger than 150 days old at the time of bleeding. In this data set, $93.2 \%$ of daughters were younger than 3 years old, while $92.3 \%$ of dams were more than 3 years old.

The seroprevalences among daughters and dams in this subset were $34.9 \%(189 / 542)$ and $37.8 \%$ (205/542), respectively. An increased risk of being seropositive was observed in daughters that were born from seropositive dams ( $\mathrm{PR}=2.6,95 \% \mathrm{CI}: 2.1-3.3)$. The proportion of daughters horizontally infected was 0.23 (95\% CI: 0.19-0.28). In this subset, 
Table 2

Probabilities of vertical ( $\left.\mathrm{AF}_{\mathrm{exp}}\right)$ and horizontal transmission of $N$. caninum

\begin{tabular}{|c|c|c|c|c|c|c|}
\hline & \multirow[t]{2}{*}{ Daughters } & \multicolumn{2}{|l|}{ Dams } & \multirow{2}{*}{$\begin{array}{l}\text { Proportion of vertical } \\
\text { transmission }(95 \% \mathrm{CI})\end{array}$} & \multirow{2}{*}{$\begin{array}{l}\text { Proportion of horizontal } \\
\text { transmission }(95 \% \mathrm{CI})\end{array}$} & \multirow{2}{*}{$\begin{array}{l}\text { Prevalence ratio } \\
(95 \% \mathrm{CI})\end{array}$} \\
\hline & & Positive & Negative & & & \\
\hline General (747 pairs) & $\begin{array}{l}\text { Positive } \\
\text { Negative }\end{array}$ & $\begin{array}{l}168[139] \\
117[96]\end{array}$ & $\begin{array}{r}81[110] \\
381[402]\end{array}$ & $\begin{array}{l}0.70(0.69,0.71) \\
{[0.64(0.62,0.66)]}\end{array}$ & $\begin{array}{l}0.18(0.14,0.21) \\
{[0.22(0.18,0.25)]}\end{array}$ & $\begin{array}{l}3.4(2.7,4.2) \\
{[2.8(2.3,3.3)]}\end{array}$ \\
\hline $\begin{array}{l}\text { Older than } 150 \text { days } \\
\text { (542 pairs) }\end{array}$ & $\begin{array}{l}\text { Positive } \\
\text { Negative }\end{array}$ & $\begin{array}{c}122[105] \\
83[71]\end{array}$ & $\begin{array}{c}67[84] \\
270[282]\end{array}$ & $\begin{array}{l}0.67(0.65,0.68) \\
{[0.62(0.60,0.63)]}\end{array}$ & $\begin{array}{l}0.20(0.16,0.25) \\
{[0.23(0.19,0.28)]}\end{array}$ & $\begin{array}{l}3.0(2.3,3.8) \\
{[2.6(2.1,3.3)]}\end{array}$ \\
\hline High (85 pairs) & $\begin{array}{l}\text { Positive } \\
\text { Negative }\end{array}$ & $\begin{array}{l}40[37] \\
14[13]\end{array}$ & $\begin{array}{l}13[16] \\
18[19]\end{array}$ & $\begin{array}{l}0.43(0.41,0.46) \\
{[0.38(0.36,0.41)}\end{array}$ & $\begin{array}{l}0.42(0.25,0.61) \\
{[0.46(0.29,0.63)]}\end{array}$ & $\begin{array}{l}1.8(1.1,2.8) \\
{[1.6(1.1,2.4)]}\end{array}$ \\
\hline Medium (154 pairs) & $\begin{array}{l}\text { Positive } \\
\text { Negative }\end{array}$ & $\begin{array}{l}37[35] \\
22[21]\end{array}$ & $\begin{array}{l}24[26] \\
71[72]\end{array}$ & $\begin{array}{l}0.60(0.58,0.62) \\
{[0.58(0.56,0.60)]}\end{array}$ & $\begin{array}{l}0.25(0.17,0.35) \\
{[0.27(0.18,0.36)]}\end{array}$ & $\begin{array}{l}2.5(1.7,3.7) \\
{[2.4(1.6,3.5)]}\end{array}$ \\
\hline Low (303 pairs) & $\begin{array}{l}\text { Positive } \\
\text { Negative }\end{array}$ & $\begin{array}{l}45[43] \\
47[45]\end{array}$ & $\begin{array}{c}30[32] \\
181[183]\end{array}$ & $\begin{array}{l}0.71(0.69,0.72) \\
{[0.70(0.68,0.71)]}\end{array}$ & $\begin{array}{l}0.14(0.09,0.19) \\
{[0.15(0.10,0.20)]}\end{array}$ & $\begin{array}{l}3.4(2.3,5.1) \\
{[3.3(2.2,4.8)]}\end{array}$ \\
\hline
\end{tabular}

This table includes the overall probabilities using all pairs, the probabilities when daughters younger than 150 days were excluded and the probabilities of the latter data-set stratified to high, medium and low within-herd seroprevalence. PR is included as measure of association. Numbers and output between square brackets correspond to values adjusted for the proportion of dams infected horizontally. 
Table 3

Multivariate analysis of the relation between seropositivity to $N$. caninum for daughters with serostatus of the dam at sampling, age of the daughter and the within-herd seroprevalence

\begin{tabular}{|c|c|c|c|c|c|c|}
\hline Factor & Level & $\begin{array}{l}\text { Frequency } \\
(\%)\end{array}$ & $\begin{array}{l}\text { Prevalence } \\
\text { (daughters) }\end{array}$ & $\beta(95 \% \mathrm{CI})$ & OR $(95 \% \mathrm{CI})$ & $P$ \\
\hline \multirow{2}{*}{$\begin{array}{c}\text { Serostatus of } \\
\text { the dam at } \\
\text { sampling }\end{array}$} & Seronegative & 61.8 & 0.18 & - & 1.0 & - \\
\hline & Seropositive & 38.2 & 0.59 & $1.79(1.62,1.97)$ & $6.0(5.1,7.2)$ & 0.000 \\
\hline \multirow{2}{*}{$\begin{array}{l}\text { Age of the } \\
\text { daughter at } \\
\text { sampling }\end{array}$} & $>150$ days & 72.6 & 0.35 & - & 1.0 & - \\
\hline & $\leq 150$ days & 27.4 & 0.28 & $-0.72(-1.34,-0.10)$ & $0.5(0.3,0.9)$ & 0.023 \\
\hline \multirow{3}{*}{$\begin{array}{l}\text { Within-herd } \\
\text { seroprevalence }\end{array}$} & High & 15.7 & 0.62 & - & 1.0 & - \\
\hline & Medium & 28.4 & 0.40 & $0.49(0.09,0.89)$ & $1.6(1.1,2.4)$ & 0.021 \\
\hline & Low & 55.9 & 0.25 & $1.21(0.75,1.52)$ & $3.4(2.1,4.6)$ & 0.000 \\
\hline
\end{tabular}

The proportion of the total variance contributed by the herd-level variance component $(\rho$, rho) was 17.8 , where $\rho=\sigma_{v}^{2} /\left(\sigma_{v}^{2}+1\right), \log$ of standard deviation $=-1.52$, standard deviation $\left(\sigma_{v}\right)=0.46$.

the probability of vertical transmission resulting in antibodies was 0.62 (95\% CI: $0.60-0.63$ ) (Table 2).

In herds with high, medium and low within-herd seroprevalence, the probability of horizontal transmission increases as the within-herd seroprevalence increases while the probability of vertical transmission decreases as the within-herd seroprevalence increases. (Tables 2 and 3).

The multivariate logistic regression with herd as random effect showed a significant 6.0-fold increased odds for being seropositive when born from a seropositive mother. Also the within-herd seroprevalence level was significantly associated with the sero-status of the daughters (Table 3). The inclusion of the herd effect showed that $18 \%$ of the variation is due to herd related factors that were not included in the analysis.

\section{Discussion}

\subsection{General}

In this study, we were able to estimate both vertical and horizontal transmission of $N$. caninum, because of the presence of seropositive daughters born from seropositive dams, as well as seropositive daughters born from seronegative dams. We are aware that the results of this study can be partially biased because the study design used is not an optimal one for making accurate and high quality estimates about the impact of vertical and horizontal transmission. For example, a dam that tested seropositive at the moment of bleeding might have been negative at the moment the calf was born. Indeed, she might have acquired the infection after parturition in a horizontal way. In a cross-sectional study this bias will lead to an underestimation of the horizontal transmission and subsequently in an overestimation of the vertical transmission. We adjusted for this at least partially by assuming that the level of horizontal transmission was equal in dams and daughters. A cohort study, as has been 
carried out by Davison et al. (1999a,b), in which both dam and daughter are bled at the moment of parturition would give better information about the sero-status at the moment of birth, and when seroconversion occurred.

Other sources of misclassification can be: variation in antibody titers throughout pregnancy (Conrad et al., 1993; Hemphill et al., 2000; Stenlund et al., 1999; Maley et al., 2001), a transient rise of antibody titers in daughters without a true Neospora infection (Hietala and Thurmond, 1999) and the limitation of an imperfect diagnostic test with a relatively low sensitivity (0.88) compared to the specificity (0.97). However, it is very unlikely that these potential sources of bias affect the results to a large extent (e.g. true prevalence in both daughters and dams hardly change after correction for imperfect SE and SP). Also, there is still a lack of information about the behavior of the infection and the course of antibody titers over time in naturally infected cattle.

\subsection{Vertical and horizontal transmission}

Under the assumption that horizontal transmission in dams and daughters is equal, we adjusted for the horizontal infection in dams. Then, the proportion of animals infected vertically reduces from 0.70 to 0.64 , while the proportion of horizontal infection increases from 0.18 to 0.22 (Table 2, all pairs). When excluding animals that might still have colostral antibodies, the proportion of vertical transmission reduces from 0.64 (all pairs) to 0.62 (542 pairs). As both proportions are quite similar it can be concluded that presence of colostral antibodies has little influence on the outcome of the proportion of animals vertically or horizontally infected. Hietala and Thurmond (1999) determined that colostral anti-Neospora antibodies decayed at 128 days after parturition. In our study, seropositive daughters fewer than 150 days could be positive due to intra-uterine infection and/or horizontal infection and/or colostral antibodies. It is possible that in those daughters under 150 day of age, antibodies titers were not increased much by colostral uptake, and the presence of antibodies was mainly due to intra-uterine infection and/or postnatal acquired infection, as in the group older than 150 days. The probabilities of vertical infection that were found in this study were lower than in other studies that used blood samples before ingestion of colostrum. Those studies reported probabilities of vertical infection over 0.80 (Paré et al., 1996; Schares et al., 1998; Davison et al., 1999a; Hietala and Thurmond, 1999). However, in two other cross-sectional studies, carried out in Spain (Mainar-Jaime et al., 1999) and Canada (Bergeron et al., 2000), the rates of vertical transmission, calculated as $\mathrm{AF}_{\text {exp }}$, were lower than $60.0 \%$. The authors of those studies conclude that the low vertical transmission rate could be due to differences related to environmental conditions resulting in an increased efficiency of horizontal transmission. Secondly, the low probability of vertical transmission found in our study may be due to a continuous stimulation of the maternal immune system in conditions of endemicity. Under these conditions, dams might be frequently exposed to environmental sources of the parasite, leading to a continuous stimulation of the immune system sufficient to prevent the exposure of the foetus to an infective dose of tachyzoites (Paré et al., 1996). However, there is no conclusive evidence about the role of the maternal immune system in prevention of vertical transmission of neosporosis. Thirdly, antibody concentrations may decline to a level below the detection limit when the infection occurred a long time ago. This might explain some cases in which 
mothers were negative while daughters were positive. This fluctuation in antibody titres for Neospora was demonstrated by Maley et al. (2001) in experimentally infected cattle. We do not have firm evidence that indicates a different behaviour in naturally infected cows.

In our study, we observed an increased probability of horizontal transmission as the within-herd seroprevalence increased, whereas the probability of vertical infection decreased at the same time. This seroprevalence related probability of horizontal transmission might be explained by an increased exposure to environmental sources of infection. These could include infected placentas or amniotic fluid (Ho et al., 1996, 1997; Bergeron et al., 2001) or food and water contaminated with Neospora oocysts from naturally infected dogs (Dubey, 1999).

\subsection{Age-specific results}

A higher seroprevalence for daughters in the age-class between 1 and 3 years old was observed (Fig. 1). This was also observed by Dijkstra et al. (2001). The differences in seroprevalence by age-classes in daughters might be due to a point source of infection as suggested by others (McAllister et al., 1996, 2000; Dijkstra et al., 2001). Furthermore, there might have been unrecognised host and/or environmental factors just previously to the reproductive age, which promotes the horizontal acquisition of the infection. This strongly suggests that horizontal transmission is present in the studied dairy herds, but that the level of it may not be constant over time. Other studies reported no difference in seroprevalence by age-classes, suggesting that the horizontal transmission plays a minimal role in the transmission of the disease (Davison et al., 1999a,b). However, by means of mathematical models, it was estimated that in the presence of imperfect vertical transmission, that without horizontal transmission prevalence of the disease has to decline over time (French et al., 1998, 1999). Our study supports this finding. The seroprevalences for the dams in all age-classes of the daughters were not different but seroprevalences do differ between age categories of daughters (Fig. 2), which might indicate that the serostatus of the daughters was not solely due to vertical infection.

In Costa Rica, veterinary practitioners have used the serostatus of an animal to predict the serostatus of its mother or its off-spring. This attitude was based on studies showing vertical transmission rates of over 80\% (Paré et al., 1996; Schares et al., 1998; Davison et al., 1999a; Hietala and Thurmond, 1999). However, under the specific conditions of the dairy herds involved in this study, the serostatus of the mother should be not used as a predictor of the serostatus of her daughter(s), because of the much lower probability of vertical transmission.

\section{Acknowledgements}

The authors are very grateful with the staff of CRIPAS project (Escuela de Medicina Veterinaria-Universidad Nacional) because of the supply of the data and other facilities. We also want to thank SAIL (Stichting Samenwerkings Verband IO-instellingen, Wageningen Universiteit, The Netherlands) and RESAP (Regional Center for Training and Research 
on Sustainable Animal, Universidad Nacional, Costa Rica) for the financial support of this investigation.

\section{References}

Anderson, M.L., Palmer, C.W., Thurmond, M.C., Picanso, J.P., Blanchard, P.C., Breitmeyer, R.E., Layton, W., McAllister, M., Daft, B., Kinde, H., Read, D., Dubey, J.P., Conrad, P.A., Barr, B.C., 1995. Evaluation of abortions in cattle attributable to neosporosis in selected dairy herds in California. J. Am Vet. Med. Assoc. 9, 1206-1210.

Anderson, M.L., Andrianarivo, A.G., Conrad, P.A., 2000. Neosporosis in cattle. Anim. Reprod. Sci. Anim. Reprod. Sci. 60-61, 417-431.

Bergeron, N., Fecteau, G., Paré, J., Martineau, R., Villenueve, A., 2000. Vertical and horizontal transmission of Neospora caninum in dairy herds in Quebec. Can Vet. J. 41, 464-467.

Bergeron, N., Girard, C., Paré, J., Fecteau, G., Robinson, J., Baillargeon, P., 2001. Rare detection of Neospora caninum in placentas from seropositive dams giving birth to full-term calves. J. Vet. Diagn. Invest. 13, $173-175$.

Boulton, J.G., Gill, P.A., Cook, R.W., Fraser, G.C., Harper, P.A.W., Dubey, J.P., 1995. Bovine Neospora abortion in north-eastern New South Wales. Aust. Vet. J. 72, 119-120.

Conrad, P.A., Sverlow, K., Anderson, M., Rowe, J., BonDurant, R., Tuter, G., Breitmeyer, R., Palmer, C., Thurmond, M., Ardans, A., Dubey, J.P., Duhamel, G., Barr, B., 1993. Detection of serum antibody responses in cattle with natural or experimental Neospora infections. J. Vet. Diagn. Invest. 5, 572-578.

Davison, H.C., Otter, A., Trees, A.J., 1999a. Estimation of vertical and horizontal transmission parameters of Neospora caninum infections in dairy cattle. Int. J. Parasitol. 29, 1683-1689.

Davison, H.C., French, N.P., Trees, A.J., 1999b. Herd-specific and age-specific seroprevalence of Neospora caninum in 14 British dairy herds. Vet. Rec. 144, 547-550.

De Marez, T., Liddell, S., Dubey, J.P., Jenkins, M.C., Gasbarre, L., 1999. Oral infection of calves with Neospora caninum oocysts from dogs, humoral and cellular immune responses. Int. J. Parasitol. 29, 1647-1657.

Dijkstra, T., Barkema, H.W., Eysker, M., Wouda, W., 2001. Evidence of post-natal transmission of Neospora caninum in Dutch dairy herds. Int. J. Parasitol. 31, 209-215.

Dijkstra, T., Barkema, H.W., Eysker, M., Hesselink, J.W., Wouda, W., 2001. Natural transmission routes of Neospora caninum between farm dogs and cattle. Vet. Parasitol. 105, 99-104.

Dubey, J.P., 1999. Neosporosis in cattle, biology and economic impact. J. Am Vet. Med. Assoc. 214, 1160-1163.

Dubey, J.P., Jenkins, M.C., Adams, D.S., McAllister, M.M., Anderson-Sprecher, R., Baszler, T.V., Kwok, O.C., Lally, N.C., Bjorkman, C., Uggla, A., 1997. Antibody responses of cows during an outbreak of neosporosis evaluated by indirect fluorescent antibody test and different enzyme-linked immunosorbent assays. J. Parasitol. 83, 1063-1609.

Dyer, R.M., Jenkins, M.C., Kwok, O.C., Douglas, L.W., Dubey, J.P., 2000. Serologic survey of Neospora caninum infection in a closed dairy cattle herd in Maryland, risk of serologic reactivity by production groups. Vet. Parasitol. 90, 171-181.

French, N.P., Davison, H.C., Clancy, D., Begon, M., Trees, A.J., 1998. Modelling of Neospora species infection in dairy cattle: the importance of horizontal and vertical transmission and differential culling. In: Proceedings of the Society of Veterinary Epidemiology and Preventive Medicine, Ennis, 25-27 March, p. 113-122.

French, N.P., Clancy, D., Davison, H.C., Trees, A.J., 1999. Mathematical models of Neospora caninum infection in dairy cattle, transmission and options of control. Int. J. Parasitol. 41, 464-467.

Hemphill, A., Gottstein, B., Conraths, F.J., de Meerschman, F., Ellis, J.T., Innes, E.A., McAllister, M.M., Mora, L.M., Tenter, A.M., Trees, A.J., Uggla, A., Williams, D.J.L., Wouda, W., 2000. A European perspective on Neospora caninum. Int. J. Parasitol. 30, 877-924.

Hietala, S.K., Thurmond, M.C., 1999. Postnatal Neospora caninum transmission and transient serologic responses in two dairies. Int. J. Parasitol. 29, 1669-1676.

Ho, M.S., Barr, B.C., Rowe, J.D., Anderson, M.L., Sverlow, K.W., Packham, A., Marsh, A.E., Conrad, P.A., 1997. Detection of Neospora sp. from infected bovine tissues by PCR and probe hybridization. J. Parasitol. 83, $508-514$ 
Ho, M.S., Barr, B.C., March, A.E., Anderson, M.L., Rowe, J.D., Tarantal, A.F., Hendrickx, A.G., Sverlow, K., Dubey, J.P., Conrad, P.A., 1996. Identification of bovine Neospora parasites by PCR amplification and specific small-subunit rRNA sequence probe hybridization. J. Clin. Microbiol. 34, 1203-1208.

Jenkins, M.C., Caver, J.A., Bjorkman, C., Anderson, T.C., Romand, S., Vinyard, B., Uggla, A., Thulliez, P., Dubey, J.P., 2000. Serological investigation of an outbreak of Neospora caninum-associated abortion in a dairy herd in southeastern United States. Vet. Parasitol. 94, 17-26.

Maley, S.W., Buxton, D., Thomson, K.M., Schriefer, C.E., Innes, E.A., 2001. Serological analysis of calves experimentally infected with Neospora caninum, a 1-year study. Vet. Parasitol. 96, 1-9.

McAllister, M.M., Huffman, E.M., Hietala, S.K., Conrad, P.A., Anderson, M.L., Salman, M.D., 1996. Evidence suggesting a point source exposure in an outbreak of bovine abortion due to neosporosis. J. Vet. Diagn. Invest. 8, 355-357.

McAllister, M.M., Dubey, J.P., Lindsay, D.S., Jolley, W.R., Wills, R.A., McGuire, A.M., 1998. Dogs are definitive host of Neospora caninum. Int. J. Parasitol. 28, 1473-1478.

McAllister, M.M., Bjorkman, C., Anderson-Sprecher, R., Rogers, D.G., 2000. Evidence of point-source exposure to Neospora caninum and protective immunity in a herd of beef cows. J. Am. Vet. Med. Assoc. 217, 881-887.

Mainar-Jaime, R.C., Thurmond, M.C., Berzal-Herranz, B., Hietala, S.K., 1999. Seroprevalence of Neospora caninum in dairy cows in the northern Spain. Vet. Rec. 17, 72-75.

Maley, S.W., Buxton, D., Thomson, K.M., Schriefer, C.E., Innes, E.A., 2001. Serological analysis of calves experimentally infected with Neospora caninum, a 1-year study. Vet. Parasitol. 96, 1-9.

Noordhuizen, J.P.T.M., Buurman, J., 1984. Veterinary automated management and production control program for dairy farms (VAMPP). The application of MUMPS for data processing. Vet. Q. 6, 62-77.

Otter, A., Jeffrey, M., Griffiths, I.B., Dubey, J.P., 1995. A survey of the incidence of Neospora caninum infection in aborted and stillborn bovine fetuses in England and Wales. Vet. Rec. 136, 602-606.

Paré, J., Hietala, S.K., Thurmond, M.C., 1995. An enzyme-linked immunosorbent assay (ELISA) for serological diagnosis of Neospora sp. Infection in cattle. J. Vet. Diagn. Invest. 7, 352-359.

Paré, J., Thurmond, M.C., Hietala, S.K., 1996. Congenital Neospora caninum infection in dairy cattle and associated calfhood mortality. Can J. Vet. Res. 60, 133-139.

Pérez, E., González, O., Dolz, G., Morales, J., Barr, B., Conrad, P.A., 1998. First report of bovine neosporosis in dairy cattle in Costa Rica. Vet. Rec. 142, 520-521.

Piergili-Fioretti, D., Rosignoli, L., Ricci, G., Moretti, A., Pasquali, P., Polidori, G.A., 2000. Neospora caninum infection in a clinically healthy calf, parasitological study and serological follow-up. J. Vet. Med. B Infect Dis. Vet. Public Health 47, 47-53.

Romero, J.J., Dolz, G., Perez, E., 2000. Neosporosis (Neospora caninum): nuevos conceptos y una descripción preliminar de su situación en Costa Rica. In: Proceedings XVII Panamerican Veterinary Congress. Panamá, Republica de Panamá, 11-15 September 2000, p. 112.

Romero, J.J., Perez, E., Dolz, G., Frankena, K, 2002. Seroprevalence and factors associated with Neospora caninum serostatus in cattle of 20 specialised Costa Rican dairy herds. Prev. Vet. Med 53, 263-273.

Schares, G., Peters, M., Wurm, R., Barwald, A., Conraths, F.J., 1998. The efficiency of vertical transmission of Neospora caninum in dairy cattle analysed by serological techniques. Vet. Parasitol. 80, 87-98.

StataCorp., 1999. Stata Statistical Software, Release 6.0. Stata Corporation, College Station, TX, USA.

Stenlund, S., Kindahl, H., Magnusson, U., Uggla, A., Bjorkman, C., 1999. Serum antibody profile and reproductive performance during two consecutive pregnancies of cows naturally infected with Neospora caninum. Vet. Parasitol. 85, 227-234.

Thilsted, J.P., Dubey, J.P., 1989. Neosporosis-like abortions in a herd of dairy cattle. J. Vet. Diagn. Invest. 1, 205-209.

Thrusfield, M., Ortega, C., de Blas, I., Noordhuizen, J.P., Frankena, K., 2001. WIN EPISCOPE 2.0: improved epidemiological software for veterinary medicine. Vet. Rec. 148, 567-572.

Thurmond, M.C., Hietala, S.K., Blanchard, P.C., 1997. Herd-based diagnosis of Neospora caninum-induced endemic and epidemic abortion in cows and evidence for congenital and postnatal transmission. J. Vet. Diagn. Invest. 9, 44-49.

Tizard, I.R, 2000. Veterinary Immunology, an Introduction, sixth ed. Saunders, Philadelphia, USA, 482 pp.

Uggla, A., Stenlund, S., Holmdahl, O.J., Jakubek, E.B., Thebo, P., Kindahl, H., Bjorkman, C., 1998. Oral Neospora caninum inoculation of neonatal calves. Int. J. Parasitol. 28, 1467-1472. 
Venturini, M.C., Venturini, L., Bacigalupe, D., Machuca, M., Echaide, I., Basso, W., Unzaga, J.M., Di Lorenzo, C., Guglielmone, A., Jenkins, M.C., Dubey, J.P., 1999. Neospora caninum infections in bovine foetuses and dairy cows with abortions in Argentina. Int. J. Parasitol. 29, 1705-1708.

Williams, D.J., Guy, C.S., McGarry, J.W., Guy, F., Tasker, L., Smith, R.F., MacEachern, K., Cripps, P.J., Kelly, D.F., Trees, A.J., 2000. Neospora caninum-associated abortion in cattle, the time of experimentally-induced parasitaemia during gestation determines foetal survival. Parasitology 121, 347-358.

Wouda, W., Moen, A.R., Schukken, Y.H., 1998. Abortion risk in progeny of cows after a Neospora caninum epidemic. Theriogenology 49, 1311-1316.

Wouda, W., Bartels, C.J.M., Moen, A.R., 1999a. Characteristics of Neospora caninum-associated abortion storms in diary herds in The Netherlands (1995 to 1997). Theriogenology 52, 233-245.

Wouda, W., Dijkstra, T., Kramer, A.M., van Maanen, C., Brinkhof, J.M., 1999b. Seroepidemiological evidence for a relationship between Neospora caninum infections in dogs and cattle. Int. J. Parasitol. 29, 1677-1682. 